\title{
Cooperación internacional y formalización de la propiedad rural en Mahates - Bolívar: Proyecto Piloto de Tierras
}

\author{
International Cooperation And Formalization Of Rural Property \\ In Mahates - Bolivar: Land Pilot Project
}

Ariel Humberto Puello Orozco y yuan Gabriel Acosta Castro

Copyright: $\odot 2019$

Revista Internacional de Cooperación y Desarrollo.

Esta revista proporciona acceso abierto a todos sus contenidos bajo los términos de la licencia creative commons AtribuciónNoComercial-SinDerivar 4.0 Internacional (CC BY-NC-ND 4.0)

Tipo de artículo: artículo resultado de ivestigación Recibido: octubre de 2019

Revisado: noviembre de 2019

Aceptado: noviembre de 2019

\section{Autores}

1 Abogado, magíster en cooperación internacional y desarrollo, especialista en seguridad social. Docente Universitario. Inspector del Trabajo y Seguridad Social. Integrante grupo de investigación GIELACID.

ORCID 0000-0002-4837-2319

Correo electrónico: arielpuelloorozco@gmail.com

2 Abogado. Magíster en derecho. Docente tiempo completo Facultad de Derecho y Ciencias Políticas de la Universidad de San Buenaventura Cartagena. Integrante grupo de investigaciones CIELACID.

ORCID 0000-0003-4728-7187

Correo electrónico: jacostacastro2@gmail.com

jacosta@usbctg.edu.co

\section{Cómo citar:}

Puello, A. y Acosta, J. (2019). Cooperación internacional y formalización de la propiedad rural en Mahates - Bolívar: Proyecto Piloto de Tierras. Revista Internacional de Cooperación y Desarrollo. 6(2). 108-132

DOI $10.21500 / 23825014.4534$
Resumen

En este artículo se presenta el análisis del resultado dos (2) del proyecto piloto de tierras de los nuevos territorios de paz financiado por la Unión Europea y su implementación en el Municipio de Mahates, Bolívar, a partir del cual se determinó la incidencia de la cooperación internacional sobre la formalización de la propiedad rural en dicho Municipio. El trabajo se llevó a cabo desde un enfoque cualitativo a modo de estudio de caso. Para la recolección de información se recurrió a la investigación documental y se aplicaron entrevistas semi-estructuradas a funcionarios y beneficiarios del proyecto escogidos de forma no probabilística, para luego proceder a la sistematización y análisis de información obtenida de fuentes tanto primarias como secundarias, a la luz del marco teórico.

La investigación determinó que el impacto del proyecto piloto de tierras sobre la formalización de la propiedad en Mahates fué prácticamente nulo pues no se legalizó ningún predio, no obstante haberse cumplido en forma satisfactoria con el resultado propuesto que consistía en un acompañamiento o asesoría técnico - jurídica. Corroboró a su vez la poca eficacia de la cooperación internacional para materializar políticas concebidas en los ámbitos nacional e internacional en pro del desarrollo, así como la precaria situación de la propiedad de la tierra que caracteriza el campo colombiano, entre otros aspectos.

Palabras clave: formalización; cooperación; desarrollo rural; derecho de propiedad.

\section{Abstract}

This article presents the analysis of the second result of the pilot land project of the new peace territories (funded by the European Union) and its implementation in the Municipality of Mahates - Bolivar. The incidence of international cooperation on the formalization of rural property in it Municipality was determined. The work was carried out from a qualitative approach as a case study. For the collection of information, documentary research was used and semi-structured interviews were applied to officials and project beneficiaries chosen in a non-probabilistic manner, based on the availability of them, and then proceeded with the systematization and analysis of information obtained from sources both primary and secondary, in light of the theoretical framework. 
The research determined that the impact of the pilot land project on the formalization of the property in Mahates was practically null because no property was legalized, despite having met in a moderately satisfactory manner with the proposed result that consisted basically of a technical-legal accompaniment or advice. It corroborated in turn the ineffectiveness of international coopera-

\section{Introducción}

La falta de acceso por parte de los campesinos a la propiedad de la tierra en Colombia y la informalidad en la tenencia de la misma, han marcado gran parte de la historia contemporánea del país. Evidencia de esto fueron las constantes movilizaciones campesinas que vivió el país a lo largo del siglo $\mathrm{xx}$ que fueron tomadas por fundamento para la formación de la que fuera la guerrilla más antigua del continente, las FARC - EP (FARC-EP, 1993), la escasa variación del coeficiente de GINI que se mantiene entre el 0.8 y el 0.9 desde 1960 según los datos del Instituto Geográfico Agustín Codazzi (2012) en cuanto a la concentración de la tierra, las varias iniciativas legislativas sobre tierras que se surtieron a lo largo del siglo xx y los primeros años del presente siglo como la ley 200 de 1936, la ley 135 de 1961, el acuerdo de Chicoral, la ley 4 de 1973, la ley 160 de 1994 y la ley 1448 de 2011, entre otros acontecimientos históricos. ${ }^{1}$

Todos estos hechos encuentran un punto de convergencia en el "Acuerdo final para la terminación del conflicto y la construcción de una paz estable y duradera" (en adelan-

' Los hechos en mención han sido ampliamente desarrollados por autores como Marco Palacios (2011) en su libro "¿De quién es la tierra?: propiedad, politización y protesta campesina en la década de 1930" y Catherine LeGrand (1988) en su libro "Colonización y protesta campesina en Colombia". Otro texto que aborda este asunto es el libro denominado "La política de reforma agraria y tierras en Colombia. Esbozo de una memoria institucional" (Centro Nacional de Memoria Histórica, 2013). Los textos mencionados son aproximaciones desde un punto de vista histórico a los hechos que han propiciado las actuales condiciones de tenencia de la tierra en el sector rural y sirvieron para contextualizar de mejor manera el problema que se aborda en el presente artículo. tion to materialize policies conceived at the national and international levels for development, as well as the precarious situation of land ownership that characterizes the Colombian countryside, among other aspects.

Keywords: formalization; cooperation; rural development; property rights.

te, Acuerdo de Paz) suscrito el pasado 24 de noviembre de 2016 (Gobierno Nacional de Colombia - FARC EP, 2016). Este documento que constituye un hito histórico en Colombia, renueva la importancia del problema que aquí se estudia, principalmente por consagrar en su capítulo primero el tema de la reforma rural. En este, toma protagonismo el concepto de Reforma Rural Integral que debe entenderse como un género, dentro del cual la reforma agraria ocupa un espacio importante.

La reforma rural es explicada por el profesor Absalón Machado (2009), al definirla como un:

(...) proceso de cambio y transformación de las estructuras rurales y de sus relaciones no sólo con los sectores agroindustrial, financiero y comercial, también con la sociedad y con la capacidad de crear las condiciones para un desarrollo agrícola más competitivo y endógeno; para un desarrollo rural más equitativo, sostenible, eficiente y sin exclusiones de ninguna naturaleza (Machado, 2009, p.98).

En los anteriores términos, se puede afirmar que la reforma rural se distingue de la reforma agraria en que, mientras en esta, la pretensión principal es la redistribución de la propiedad en beneficio de campesinos sin tierra o con tierra insuficiente, la reforma rural va más allá, pues busca adicionalmente el acceso a los activos productivos (como la tierra), formación de capital social, una nueva institucionalidad agraria, la consideración del territorio como eje para la 
planeación y ejecución de las políticas, entre otros aspectos (Machado, 2009, pp.9899). Es decir, la reforma agraria es parte de la reforma rural.

Lo anterior permite comprender cómo sin un desarrollo rural equitativo no puede presentarse una reforma rural. En esta relación, la formalización de la propiedad ocupa un renglón privilegiado, debido a que incide directamente en la disminución de los altos niveles de desigualdad en el campo. De hecho, la informalidad en la tenencia de la tierra es un problema que caracteriza al menos el 50\% de los predios en las zonas rurales del país (Banco Mundial, 2013), lo que representa un obstáculo para que la población rural acceda a recursos financierosy adquiera estabilidad.

La informalidad no obstante es un tema que no se aprecia adecuadamente si no se analiza en conjunto con los demás problemas de la tierra en Colombia como son la desactualización del catastro rural, la no integración del catastro y el registro de propietarios, el desconocimiento de los baldíos de la nación, un patrón inadecuado de ocupación y uso de la tierra, debilidad y corrupción institucionales. De estos problemas se derivan otros en un segundo nivel: Concentración y acaparamiento, por una parte, y despojo y abandono por otra. Ante este panorama no es arriesgado afirmar que en el país persisten los mismos problemas relacionados con la tierra de hace cien años. Como lo expresa Absalón Machado (2009) "Colombia no ha resuelto su problema agrario y la reforma agraria es un fantasma que se aparece con frecuencia".

Todos estos problemas se encuentran de una $u$ otra manera presentes a lo largo y ancho del país. Es por esto que a partir del año 2014 se inició en algunos municipios de los departamentos de Atlántico, Bolívar, Magdalena, Guaviare y Caquetá el proyecto denominado "Piloto de Tierras" el cual fue ejecutado por la Organización Internacio- nal para las Migraciones (En adelante OIM). Este proyecto hizo parte del programa Nuevos Territorios de Paz financiado por la Unión Europea (En adelante UE) con recursos de contrapartida del Departamento para la Prosperidad Social del Colombia (En adelante DPS). El proyecto tuvo como objetivo general "promover la tenencia, acceso, ordenamiento y uso del territorio de manera segura, sostenible y democrática para mitigar conflictos, el desarrollo y la paz de acuerdo al contexto y necesidades específicas de los nuevos territorios de Paz" y para su ejecución, se proyectaron una serie de acciones a realizar en el curso de dos años.

Este trabajo se plantea como un estudio de caso del anterior proyecto, específicamente del resultado segundo relativo a la formalización de la propiedad a partir las acciones desarrolladas en el municipio de Mahates - Bolívar. Así, con miras al basto escenario de cooperación para el posconflicto y la importancia relativa de este proyecto piloto para la futura implementación de programas o proyectos similares se dio respuesta a la pregunta ¿Cuál ha sido la incidencia de la Cooperación Internacional para el Desarrollo sobre la formalización de la propiedad en el municipio de Mahates - Bolívar a partir del Proyecto Piloto de Tierras?

En relación con esto, es menester delimitar el concepto de incidencia, el cual es central en el presente trabajo. En principio podemos considerar la definición de la Real Academia Española (2019), como "Influencia o repercusión". En otra acepción indica que es el "acontecimiento que sobreviene en el curso de un asunto o negocio y tiene con él alguna conexión". Es precisamente la forma y el alcance de esa influencia la que se logró dilucidar en el presente trabajo, entendiéndola como comprensión del proyecto y sus resultados, beneficios obtenidos por los participantes, aprendizaje sobre el proceso de formalización y el seguimiento 
que se dio a las solicitudes de formalización, aún después del cierre oficial del proyecto, lo que se complementó con la revisión del modelo de intervención y la percepción de los participantes.

Para dar respuesta a la pregunta de investigación se definieron los siguientes objetivos específicos: en primer lugar, identificar la forma en que la cooperación internacional ha abordado el tema de tierras en el ámbito global. En segundo lugar, describir el problema de tierras en Colombia y el proyecto "Piloto de Tierras de los Nuevos Territorios de Paz" implementado Cooperación Internacional. Finalmente, analizar los resultados de dicho programa relacionados con la formalización de la propiedad rural en el municipio de Mahates - Bolívar. Y es con esta lógica que se desarrollan los capítulos en el presente artículo: En el primero se expone la perspectiva de diferentes organismos internacionales y la cooperación (Agudelo, 2014, p.117), así como los instrumentos más relevantes sobre el tema de tierras; en el segundo se explican los problemas de la tierra en Colombia para luego en el tercer capítulo describir el caso "proyecto piloto de tierras". Finalmente se analizan los resultados del proyecto contrastando la sistematización oficial de la OIM con la versión de funcionarios públicos y beneficiarios del proyecto.

\section{Metodología}

Esta investigación se desarrolló desde un enfoque Cualitativo. Como método se optó por un estudio de caso por tratarse de un proyecto piloto culminado, cuyo análisis resulta de interés general. La población está constituida por las personas y entidades responsables de desarrollar el Proyecto Piloto de Tierras y sus beneficiarios. El tipo de muestra es no probabilística por conveniencia. Se utilizaron fuentes tanto primarias como secundarias para la recolección de información. El primer grupo, lo constituyen seis (6) personas entre beneficiarios residentes en la vereda paraíso, el corregimiento de Malagana y el casco urbano del municipio de Mahates y funcionarios públicos como son el director de la Umata y el inspector de Malagana. Estos dieron su consentimiento informado para la aplicación de entrevistas semi-estructuradas, técnica de recolección seleccionada para esta fase. Como fuente secundaria se acudió a documentos institucionales del proyecto, normas, libros, revistas, entre otras, utilizando como técnica, la revisión documental.

La información recolectada a través de las entrevistas se transcribió y tabulo a partir de las preguntas que conformaron la misma, así:

\begin{tabular}{|c|c|c|c|c|c|c|c|c|}
\hline ENTREVISTADO & 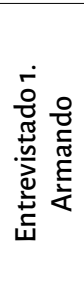 & 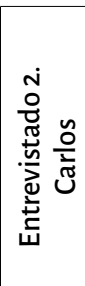 & 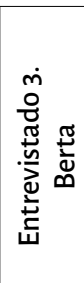 & 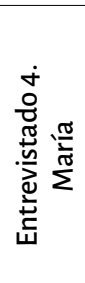 & 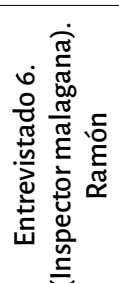 & 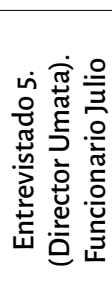 & 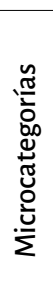 & 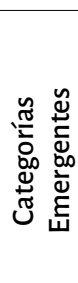 \\
\hline Lugar de residencia u oficina & & & & & & & & \\
\hline $\begin{array}{l}\text { Tiene claridad sobre los aspectos generales del } \\
\text { proyecto como: ¿año de realización, forma de } \\
\text { comvocatoria o finalidad del mismo? }\end{array}$ & & & & & & & & \\
\hline ¿Partició del proyecto? ¿En que calidad? & & & & & & & & \\
\hline ¿Cómo se enteró del proyecto & & & & & & & & \\
\hline
\end{tabular}

Fuente: elaboración propia 
Del cuadro resultante surgieron, luego de un análisis inductivo orientado por la información documental, algunas categorías emergentes, como son: convocatoria, incidencia, percepción frente a los resultados y modelo de intervención. En primer lugar, la convocatoria es la etapa del proyecto en la cual se vinculó a los participantes al mismo. Describe los mecanismos utilizados para su divulgación y promoción. En segundo lugar, la incidencia, como antes se definió, se refiere a la influencia o repercusión que tuvo el proyecto durante su desarrollo y respecto de sus resultados. Implica algunas micro categorías que la determinan, como son: comprensión del proyecto y sus resultados, beneficios obtenidos por los participantes, aprendizaje sobre el proceso de formalización y el seguimiento que se dio a las solicitudes de formalización, aún después del cierre oficial del proyecto. En tercer lugar, la percepción frente a los resultados, que se refiere a la opinión informada o valoración general que expresaron los beneficiarios y funcionarios públicos que intervinieron en el proyecto de la OIM. En cuarto lugar, el modelo de intervención, que describe la metodología utilizada la OIM como ejecutor del proyecto para el logro del resultado establecido en el marco lógico. Una vez colectada la información y sistematizada se procedió a su validación a la redacción del informe final.

\section{Discusión de los resultados}

\section{Perspectiva internacional sobre la}

tierra

La cooperación internacional en temas de tierra inicia en los años cuarenta del siglo pasado debido a la preocupación creciente por la seguridad alimentaria, la cual generó para la comunidad internacional la necesidad de impulsar el desarrollo rural en países emergentes. Dicha preocupación persiste hoy día, sumándose a otras como la erosión del suelo, la salinización de tierras de regadío, la reducción de la biodiversidad y el cambio climático que entraron en la agenda hacia los años ochenta y noventa (FAO, 2012b, pp.102-103).

Si bien el tema de tierras y la forma en que estas se administren pertenecen a decisiones soberanas de los Estados, el bienestar global (que en últimas es también bienestar local) amerita que estas se tomen en consideración a los grandes problemas que afectan la sostenibilidad del planeta. Es por esto que en diversas conferencias internacionales se ha avanzado en la definición de principios cada vez más claros como los relativos a la ordenación sostenible de los bosques (ONU, 1992), la gestión integrada de los recursos hídricos (ONU, 2010) y la lucha contra la desertificación (ONU, 17 de junio de 1994). (FAO, 2012b, p.103).

La cooperación internacional ha facilitado el acceso de algunos países a recursos financieros y técnicos. Según datos del Banco Mundial (2018) hasta la fecha se han desarrollado 733 proyectos ${ }^{2}$ relacionados con desarrollo rural, financiados con recursos propios de esta entidad. Adicionalmente se han mejorado los incentivos para la sostenibilidad ambiental con mecanismos como "el pago por servicios ambientales (PSA), mecanismos para un desarrollo limpio (MDL) y el comercio de derechos de emisión de dióxido de carbono" (FAO, 2012b, pp.103-104).

No obstante, la cooperación no ha sido eficaz en generar cambios positivos que contribuyan al desarrollo de los países más pobres, es decir, las políticas no logran llevarse a la práctica. Tampoco ha incrementa-

\footnotetext{
${ }^{2}$ La mayor cantidad de proyectos han apuntado a servicios e infraestructuras rurales (437 proyectos) seguido de políticas e instituciones rurales ( 276 proyectos. Por otra parte, los temas sobre los que menos proyectos se han desarrollado son la administración y ordenación de la tierra que suma un total de 131 proyectos y el cambio climático con 60 proyectos en total (Banco Mundial, 2018).
} 
do la ayuda a un nivel adecuado, de acuerdo con los compromisos adquiridos y las necesidades de los países en desarrollo. En este sentido los principios y programas establecidos en el ámbito internacional "han contribuido extraordinariamente a cambiar los enfoques y las políticas, pero han tenido un impacto limitado en lo que respecta a cambiar los comportamientos" (FAO, 2012b, p.104-105).

Esto se ve reflejado en que aún en muchos países en vías de desarrollo no existan derechos claros y estables sobre la tierra (informalidad), lo que, sumado a la escasa capacidad del Estado para regular y aplicar las normas, ha contribuido a crear conflictos en torno al acceso a la misma (FAO, 2012b, p.6-8). Muchos Estados ni siquiera conocen la cantidad de tierra que poseen; las mismas están sujetas usualmente a invasiones, reclamaciones históricas o asignaciones corruptas por lo que su gestión se vuelve compleja. Por ende, cualquier reforma que se proponga para atender estas dificultades debe priorizar un registro catastral fiable, ${ }^{3}$ la protección del patrimonio estatal y acompañarse de programas complementarios que garanticen que, una vez puesta la tierra en manos de individuos o comunidades, estos tendrán los medios para su productividad (FAO, 2012b, p.207). ${ }^{4}$

La tierra es uno de los más importantes factores de producción agrícola, por lo que la forma en que esta sea administrada determinará el éxito ante los desafíos que plantea el crecimiento de la población

${ }^{3}$ Esta afirmación se complementa con la perspectiva del Banco Mundial según el cual muchos países carecen de sistemas comprehensivos de registro de las tierras que incluyan propietarios.

${ }^{4}$ Otros fenómenos relacionados con la tierra que han sido abordados por la FAO son el acaparamiento o concentración y la extranjerización. La concentración es la acumulación de la tierra en manos de un mismo actor FAO (2014, pág. 12). La extranjerización por su parte se refiere a que la titularidad de la concentración de la tierra la ostenta un estado o empresa extranjera (FAO, 2012a, p.9). mundial que se proyecta sobrepasará los nueve mil millones de personas hacia 2050 (FAO, 2012b, p. vii), representando esto un incremento de alrededor de dos mil millones respecto de la población actual ${ }^{5}$.

En este sentido la FAO ha identificado algunos problemas vinculados a la producción agrícola como son que:

1. Las políticas agrícolas se han concebido principalmente en beneficio de los agricultores con tierras productivas y acceso al agua marginando a pequeños productores. 2. Las instituciones responsables no han tenido la capacidad de adaptarse a las necesidades de producción y el cambio climático. 3. La distribución de los recursos de tierra y agua en los países en desarrollo no son propicios para el aumento sostenible de la producción (FAO, 2012b, p.xxv).

Para este organismo las acciones que adelanten los Estados en relación con las tierras deben apuntar a la adecuada distribución, administración y uso de los recursos naturales. Indica que la población pobre es la que menores posibilidades tiene de acceder a tierra y agua, lo que describe la problemática de la desigualdad en la distribución de la tierra. Según la FAO "el coeficiente de Gini-que mide la desigualdad-aplicado a la distribución de la tierra en la región (Latinoamericana) como un todo alcanza 0,79, superando ampliamente a Europa $(0,57)$, África $(0,56)$ y Asia $(0,55)$ " (Oficina Regional de la FAO para América Latina y el Caribe, 2017) Es, como afirma la misma organización, la distribución de tierras más desigual en el mundo. Los datos son aún más dramáticos cuando se aísla a Suramérica que alcanza un coeficiente de CINI de 0,85. Esta situación impide superar los niveles de pobreza en que se encuentran muchas poblaciones rurales, además de otras circunstancias como el tamaño reducido de

${ }^{5}$ La población actual asciende a los 7,632,819.325 (ONU, 2018). 
los cultivos, que se hacen sobre suelos de mala calidad, el clima cambiante y la degradación de los suelos.

En relación con esta preocupación por los bajos niveles de producción y el crecimiento de la población se debe hacer referencia también de la llamada "revolución verde" que se caracterizó por la introducción de los avances tecnológicos aplicados y a la fitogenética, es decir, se trataba de un "conjunto de tecnologías integradas por componentes materiales, como las variedades de alto rendimiento (VAR) mejoradas de dos cereales básicos (arroz y trigo), el riego o el abastecimiento controlado de agua y la mejora del aprovechamiento de la humedad, los fertilizantes y plaguicidas, y las correspondientes técnicas de gestión" (FAO, 1996).

Otras instituciones como la Organización de los Estados Americanos (OEA) se han preocupado por generar en los países que la conforman, sistemas equitativos $y$ eficaces de tenencia de la tierra y promover el aumento de la productividad agrícola.

La Coalición Internacional para el Acceso a la Tierra ${ }^{6}$ (en adelante ILC por sus siglas en inglés) como organización de sociedad civil ha venido trabajando porque cada día más países reconozcan que los derechos sobre la tierra son fundamentales para el desarrollo, la erradicación de la pobreza y el hambre. La meta común de la red se denomina "gobernanza de la tierra centrada en las personas" con lo cual se quiere responder a las necesidades, proteger los derechos de las mujeres, los hombres y comunidades que viven "en y de la tierra" respetando las decisiones que cada uno de forma libre toma sobre el uso de esta y sobre los recursos que le pertenecen (Coalición Internacional para el Acceso a la Tierra, 2015, p.19).

Entre los compromisos adquiridos por parte de las organizaciones vinculadas se

${ }^{6}$ Es una red que articula la acción de más de 200 organizaciones de sociedad civil e intergubernamentales ubicadas en más de 60 países. Creada en 1995. Su página web es https://www.landcoalition.org/es encuentran la promoción de derechos de tenencia seguros, sistemas agrícolas en pequeña escala sólidos, diversidad en los sistemas de tenencia (que incluye la tenencia comunal), igualdad en los derechos a la tierra para las mujeres, derechos territoriales seguros para los pueblos indígenas (Coalición Internacional para el Acceso a la Tierra, 2015, p.17), entre otros.

El primer punto (Derechos de tenencia seguros) implica un esfuerzo para que las mujeres y hombres pobres conserven el uso y control de su tierra y no sean sujetos de desalojos, expulsiones, exclusiones, desplazamientos, despojo, entre otras acciones.

\section{Acuerdos internacionales}

\section{relacionados con la tierra y su gestión}

Entre los logros principales en relación con la gestión de la tierra podemos resaltar las cumbres de Rio (Convención de Rio) (ONU, 1992), del milenio (ONU, 2000) y de Johannesburgo (ONU, 2002) que constituyen el marco a partir del cual se dictan los Objetivos de Desarrollo del Milenio del año 2002. Otras convenciones relacionadas son: la Convención de Naciones Unidas de Lucha contra la Desertificación, antes citada, el Convenio sobre la Diversidad Biológica y la Convención Marco de las Naciones Unidas sobre el Cambio Climático (FAO, 2012b) y finalmente la Declaración de las Naciones Unidas sobre los derechos de los campesinos y otras personas que trabajan en zonas rurales adoptada el 17 de diciembre de 2018 y según la cual "Los campesinos y otras personas que viven en zonas rurales tienen derecho a la tierra, individual o colectivamente tienen derecho a acceder a la tierra, las masas de agua, las aguas costeras, las pesquerías, los pastos y bosques" (Artículo 12, p.2).

La Convención de las Naciones Unidas de Lucha contra la Desertificación (CLD) en los países afectados por la sequía grave o la desertificación, en particular en África es el "único acuerdo internacional jurídicamente 
vinculante que relaciona el medio ambiente y el desarrollo con la gestión sostenible de la tierra" (ONU, 2018), no obstante, no hace alusión específica al tema de la formalización de la propiedad rural que ahora nos ocupa.

En el año 2000, la ONU definió los Objetivos de Desarrollo del Milenio. Estos establecieron las metas a seguir hasta el 2015 para mejorar las condiciones de vida de las personas en países menos desarrollados. No obstante, una vez revisado el marco ampliado de metas e indicadores, ${ }^{7}$ no se registró en los ODM objetivo, meta ni indicador alguno vinculado en forma directa con el problema de la formalización de la propiedad de la tierra, ni tampoco con el análisis de cómo la cooperación internacional ha abordado el tema de tierras en el ámbito global. De hecho, el informe de 2015 de los ODM así lo evidencia cuando, en referencia al tercero de los objetivos, sobre la promoción de la igualdad de género, expresa que:

(...) todavía existen muchos vacíos, en particular en áreas que no fueron abordadas por los ODM. Para alcanzar la realización universal de la igualdad entre los géneros y el empoderamiento de la mujer, es esencial abordar las áreas clave que la generan, lo que incluye (...) el control limitado de las mujeres sobre los bienes y la propiedad (...) (ONU, 2015).

Existen entonces, aspectos importantes que no fueron considerados en los ODM; la tierra es uno de estos.

Por el contrario, en los ODS, ${ }^{8}$ aunque tampoco existe un objetivo exclusivo, es

\footnotetext{
${ }^{7}$ En el marco de monitoreo establecido para los ODM se definieron inicialmente 18 metas y 48 indicadores. No obstante, en la $62^{\mathrm{a}}$ sesión de la Asamblea Ceneral de la ONU se presentó un marco reformulado con un total de 21 metas y 60 indicadores (CEPAL, 2018)

${ }^{8}$ Se aclara que esta referencia a los ODS tiene la finalidad de brindar una perspectiva actual sobre la temática y generar un insumo adicional para la discusión. Pero, no será un criterio principal para el análisis del programa piloto de tierras, el cual se concibió hacia el año 2013 siendo su marco contextual y normativo los ODM.
}

posible identificar aspectos muy concretos que abordan el tema, sea en el marco de las metas o de los indicadores descritos en la resolución A/RES/71/313 de 10 de julio de 2017.

Para el primero de los objetivos, el cual busca poner fin a la pobreza, la comisión estableció la meta 1.4. que busca garantizar que hombres y mujeres, tengan los mismos derechos a "los recursos económicos y acceso a los servicios básicos, la propiedad y el control de la tierra y otros bienes". En correspondencia el indicador 1.4 .2 se refiere a "la proporción del total de la población adulta con derechos seguros de tenencia de la tierra que posee documentación reconocida legalmente al respecto y considera seguros sus derechos, desglosada por sexo y tipo de tenencia" (Comisión de Estadística de Naciones Unidas, 2017). Esto expresa que en la práctica la reducción de la pobreza implica necesariamente asegurar los derechos de tenencia de la tierra, especialmente para las personas pobres y vulnerables.

El objetivo número dos busca poner fin al hambre, lograr la seguridad alimentaria, la mejora de la nutrición y promover la agricultura sostenible. Para el logro de este se ha definido la meta 2.3 que busca "duplicar la productividad agrícola y los ingresos de los productores de alimentos en pequeña escala (...) entre otras cosas mediante un acceso seguro y equitativo a las tierras" (Comisión de Estadística de Naciones Unidas, 2017). En este caso se considera que el acceso la tierra permite a los campesinos mejorar sus ingresos por producción, obtener servicios financieros, ofrecer sus productos a precios competitivos en el mercado e inclusive mejorar sus condiciones de trabajo.

El objetivo número cinco busca lograr la igualdad de género y empoderar a todas las mujeres y las niñas. Para el logro del mismo se definió la meta 5.a. que plantea "emprender reformas que otorguen a las mujeres igualdad de derechos a los recursos económicos, así como acceso a la propiedad y al control de la tierra y otros tipos de bienes 
(...)". A su vez los indicadores relacionados miden la población agrícola con derechos de propiedad o derechos seguros sobre tierras agrícolas y la capacidad de los ordenamientos jurídicos de garantizar "la igualdad de derechos de la mujer a la propiedad o el control de las tierras" (Comisión de Estadística de Naciones Unidas, 2017). En este caso la propiedad o tenencia de la tierra con derechos seguros por parte de las mujeres, se concibe como un medio para promover la igualdad de género.

Los objetivos hasta aquí mencionados son los que guardan relación directa con el tema de tierras y su formalización.

\section{Los problemas de la tierra en Colombia} Bien puede decirse que el problema de la tierra en Colombia radica en no haber desarrollado con éxito una verdadera reforma agraria. Esta debió resolver desde principios del siglo xx los problemas que hoy día siguen afectando al sector rural. ${ }^{9}$ La promesa de la reforma agraria se renueva con el Acuerdo de Paz suscritos entre el Cobierno Nacional de Colombia y las FARC - EP en el año 2016, como reforma rural integral. Entre los problemas que deben ser abordados se encuentran: informalidad en la tenencia de la tierra, desactualización del catastro rural, no integración del catastro y el registro de propietarios, el desconocimiento

${ }^{9}$ Con la ley 200 de 1935 por ejemplo se buscó "afrontar" por primera vez dicha cuestión por la vía legislativa (Palacios, 2011, p.196), pero esta ley, contrario a traer un beneficio terminará perjudicando a la población rural, pues fomentó una actitud más fuerte de parte de los terratenientes para apropiarse de extensiones cada vez mayores de tierras. Detrás de la ley se escondía el interés del gobierno de Alfonso López Pumarejo (1934-1938) de recuperar el poder político privilegiando a la "Gran Empresa Agrícola” (Berry, 2002, p.32). Otros intentos de reforma agraria fueron la ley 135 de 1961 que se promulga en contexto de la Alianza para el Progreso promovida por el gobierno de los Estados Unidos y la ley 160 de 1994 que dio lugar al Ilamado mercado de tierras en el contexto de la apertura económica, proceso posterior al agotamiento del modelo de industrialización mediante sustitución de importaciones (Casilda, 2004, p.19-38). de los baldíos de la nación, un patrón inadecuado de ocupación y uso de la tierra, debilidad y corrupción institucional, la concentración y acaparamiento de tierras y el despojo y abandono.

En primer lugar, la informalidad en la tenencia de la tierra. Este es uno de los problemas más evidentes de la ruralidad colombiana. Los índices de informalidad de la propiedad en zonas rurales bordean el $50 \%$ de los predios según datos del informe de evaluación de la gobernanza de la tierra del Banco Mundial (2013). Dicha medición coincide con el informe de la misión para la transformación del campo (2015, p.20), que indica que la informalidad afecta al menos a tres quintas partes de los predios y casi la mitad de los municipios solo tiene entre o y $50 \%$ de los propietarios con títulos formales, por lo que no duda esta última en afirmar que es una característica generalizada de la tenencia de la tierra en el país.

Este problema afecta tanto a la propiedad privada como a la pública cuando se trata de bienes adjudicados a población campesina. En ambos casos, los derechos que se ostentan sobre los predios no tienen la entidad suficiente para garantizarles seguridad jurídica, es decir, no existe derecho de propiedad sino mera tenencia, posesión u ocupación.

En Colombia para adquirir la propiedad o dominio ${ }^{10}$ de un bien inmueble (como una parcela o una casa), es decir para que se surta formalmente la transmisión o la transferencia bien a otra persona, se requiere cumplir con dos pasos fundamentales: primero es la constitución del título, esto es, la celebración del contrato de venta que es el acto jurídico que genera la obligación de transmitir el dominio y el derecho correlativo de

\footnotetext{
${ }^{10}$ El artículo 669 del código civil colombiano expresa que "el dominio que se llama también propiedad es el derecho real en una cosa corporal, para gozary disponer de ella arbitrariamente, no siendo contra ley o contra derecho ajeno. La propiedad separada del goce de la cosa se llama mera o nuda propiedad".
} 
adquirirlo. En su celebración debe tenerse en cuenta lo que indica el artículo 1857 del Código civil colombiano según el cual esta no se perfecciona ante la ley, mientras no se ha otorgado escritura pública, es decir, el contrato de compraventa deberá constar en escritura pública. En segundo, una vez constituido el título se debe proceder con el "modo" que para el caso de la venta de bienes inmuebles es la tradición. "Esta última es "la forma de ejercitar el título para adquirir el derecho real" (UPRA, 2014, p.38), la cual se materializa con la entrega material del bien, pero adicionalmente con la inscripción de la escritura pública en la Oficina de Registro de Instrumentos Públicos. Si no se cumple con estos pasos no puede predicarse la existencia de un derecho de propiedad sino tan solo de tenencia que puede ser a título de posesión que se ejerce sobre bienes de naturaleza privada.

Otros contratos que pueden transmitir el dominio de bienes inmuebles son la donación y la permuta, pero también es posible adquirirlo por medio de la sucesión en caso de fallecimiento de un propietario ante lo cual sus herederos tendrían derecho a adquirirlo, y finalmente por prescripción del derecho cuando se ha poseído un bien por el término que establece la ley. Para el caso de los bienes de naturaleza pública que son los baldíos ${ }^{12}$ y los bienes del Fondo Nacional Agrario (en adelante FNA), su dominio se transmite solo mediante la adjudicación que para el efecto realiza la actual ANT y ante lo cual el beneficiario deberá proseguir con la protocolización y registro en ORIP. Se aclara que, si bien las personas

"Según el artículo 673 del código civil colombiano los modos de adquirir el dominio son: la ocupación, la accesión, la tradición, la sucesión por causa de muerte y la prescripción.

${ }^{12}$ Los baldíos se definen como bienes sobre los que no es posible acreditar propiedad privada, bien sea porque nunca han salido del patrimonio de la Nación, o bien, porque pese a haber sido de un particular, su titularidad retornó a la nación por alguno de los procedimientos previstos por la Ley 160 de 1994. pueden ocupar un predio de naturaleza pública, este hecho no da per se derecho a reclamar la propiedad como en el caso de la posesión, toda vez que estos son imprescriptibles. ${ }^{13}$

Formalizar la propiedad implica obtener la titularidad de la misma (lo cual va más allá de la mera tenencia física) y es un aspecto importante para el desarrollo rural. Según el informe de desarrollo humano (2011) "la tenencia de la tierra en Colombia es quizás el componente más importante de la estructura agraria y el que más afecta el desarrollo humano en el sector rural". Formalizar permite que la población beneficiada acceda a financiamiento a través del crédito formal y asistencia técnica, entre otros beneficios ya citados (Misión para la transformación del campo, 2015, p.20).

La formalización de la propiedad rural es parte de las estrategias de ordenamiento y desarrollo territorial propuestas por la Misión para la transformación del campo en su informe de 2015. Según esta entidad para que haya éxito en el proceso de formalización, se debe recurrir a la estrategia de barrido predial con intervenciones masivas en los municipios pues resulta más efectiva que la tramitación de solicitudes individuales (Misión para la transformación del campo, 2015, p.87), metodología que adolece de la sistematicidad con que amerita abordarse el problema de la formalización. De hecho, esta metodología fue adoptada desde el año 2012 por el Ministerio de Desarrollo Rural con base en la resolución 452 de 2010 que creó el Programa Nacional de Formalización de la Propiedad Rural, la cual fue modificada a su vez por la resolución 181 de 2013. Específicamente la guía metodológica

\footnotetext{
${ }^{13}$ La imprescriptibilidad de los bienes públicos es una disposición de orden constitucional. El artículo 63 de la Constitución Política reza: Los bienes de uso público, los parques naturales, las tierras comunales de grupos étnicos, las tierras de resguardo, el patrimonio arqueológico de la Nación y los demás bienes que determine la ley, son inalienables, imprescriptibles e inembargables.
} 
para la formalización masiva de la propiedad rural por barrido predial fue adoptada mediante resolución 347 de 2013. ${ }^{14}$

En segundo lugar, entre los problemas del campo colombiano está el desconocimiento de la totalidad de tierras que constituyen los baldíos de la Nación. Al respecto, expresa la Misión para la Transformación del Campo que:

El desorden y la inseguridad jurídica sobre la tierra parten de un problema de la administración de las tierras de la Nación. No se cuenta con un inventario de los baldíos y, como consecuencia, la tierra se ha ocupado de forma desordenada y espontánea por los particulares sin atender a la vocación del suelo (2015, p.39).

Esto, a pesar de que en Colombia el decreto 2363 de 1994 establece un procedimiento de clarificación de la propiedad y su deslinde.

En tercer lugar, la desactualización del catastro debido a que no se inscriben las mejoras, posesiones u ocupaciones, entre otros actos realizados sobre los bienes inmuebles, lo cual conlleva a la inadecuada aplicación de la plusvalía y valorización en la zonas rurales, consolidándose de esta manera las barreras para la inversión y el desarrollo (Puello, 2018, p.121).

En cuarto lugar, tenemos el problema de la ineficiencia institucional y la corrupción. Desde el año 2003 y hasta el 2015 la administración de tierras de la nación estuvo a cargo del Incoder entidad que sucedió al Incora que estuvo al frente de dicha tarea desde 1961. EL Incoder presentaba entre otros

\footnotetext{
${ }^{14}$ Dicha guía plantea que se deben establecer zonas de formalización masiva por lo que se entiende que el programa no opera en forma simultánea en todo el país. Actualmente solo opera los municipios de Moniquirá; Villa de Leyva; Ramiriquí; Sáchica; Buenos Aires; Popayán; Morales; Timbío; Piendamó; Caldono; Mercaderes; S. Quilichao; Miranda; Padilla; San Juan de Rioseco; Pitalito; San Agustín; La Unión; Jamundí; Manizales; Pereira; Ciénaga (Celac, 2019).
}

problemas la centralización de funciones, ineficacia, morosidad, insuficiencia de recursos y personal, que además en muchos casos se mostraba incompetente y corrupto por lo que se verificaron acciones como la adjudicación de baldíos a personas que no tenían la calidad de sujetos de reforma (Procuraduría Ceneral de la Nación, 2015, p.45-50).

En vista de esto, a finales del año 2015, la Presidencia de la República creó nuevas instituciones que se encargarían de la política de desarrollo rural integral. ${ }^{15}$ Las instituciones en mención son la Agencia Nacional de Tierras, La Agencia de Desarrollo Rural y la Agencia de Renovación del Territorio, las cuales están adscritas al Ministerio de Agricultura y Desarrollo Rural. Con esta reforma "se vuelve a un modelo en que se distribuyen las funciones en diferentes entidades para que las mismas no sobrepasen su capacidad de ejecución" (Puello, 2018, p.113).

Empero, la ineficiencia no es un fenómeno exclusivo de la rama ejecutiva, también ha permeado a la rama judicial. La baja productividad, la congestión y la mora judicial son problemas que casi cualquier ciudadano puede identificar en esta rama del poder público. Los mismos no pueden reducirse a la actitud de los funcionarios judiciales, sino que obedecen a causas mayores entre las que se cuentan el rezago del sistema jurídico en relación con el desarrollo del país, déficit presupuestal, el excesivo formalismo judicial, entre otros aspectos (Londoño, 2008).

Pero el problema de la justicia para el sector rural va más allá. Hasta la fecha en Colombia no se ha implementado la llamada jurisdicción agraria a pesar de haber sido establecida en dos cuerpos normativos como son la ley 200 de 1936 y el decreto 2303 de octubre 7 de 1989. En ninguno de los dos casos se logró una implementación

${ }^{15}$ Estas entidades fueron creadas a través de los decretos $2363,2364,2365,2366,2367,2369,2370,2371$ y 2372 de 2015 
exitosa. En el último se avanzó en el establecimiento de tres circuitos judiciales que con el tiempo fueron desmontados acentuando la ineficacia de la norma hasta que en el año 2012 fuera derogada por el Código general del proceso. Es por esto que la Misión para la transformación del campo (2015, p.87) reclama su creación como jurisdicción independiente o como una especialidad dentro de la jurisdicción ordinaria. Así mismo, el Acuerdo de Paz la consagró como una necesidad para la resolución de los conflictos en el sector rural según reza su numeral 1.1.8.

Otro problema fundamental es la concentración. Los datos del Censo Nacional Agropecuario del año 2014 indican que "mientras que el 69,9\% de las Unidades Productivas Agropecuarias (UPA) tiene menos de 5 hectáreas y ocupa el 4,8\% del área total censada, el $0,4 \%$ de las UPA tiene 500 hectáreas o más y representa el $40,1 \%$ del total del área" (Misión para la transformación del campo, 2015, p.19). En el mismo sentido el Instituto Geográfico Agustín Codazi y Corpoica (2012) indica que hacia el 2002 la propiedad de los predios rurales en Colombia estaba distribuida así: 0,4 por ciento de los propietarios (15.273 personas), poseían el 61,2 por ciento del área predial rural registrada (47.147.680 hectáreas distribuidas en predios en su mayoría con extensiones mayores a $500 \mathrm{ha}$ ).

El coeficiente de Gini $^{16}$ evidencia de forma más clara el alto grado de concentración de la tierra en Colombia. La Misión para la transformación del campo (2015, p.19) expresó que dicho coeficiente se mantiene en el orden del 0,8 y 0,9, valores entre los que se ubican las mediciones hechas del mismo desde el año 1960, como indica el Instituto Geográfico Agustín Codazzi (2012) en el documento Atlas de distribución de la pro-

${ }^{16}$ De acuerdo a este coeficiente un valor cercano a uno (1) indica que la posesión de la tierra se encuentra en pocos individuos, mientras que uno cercano a cero (o) indica que la tierra está distribuida en un mayor número de personas piedad rural en Colombia. En el mismo sentido la Ceelat (2016) indica que Colombia presenta la distribución más desigual de la propiedad rural de América Latina, que como vimos arriba es la región con mayor concentración de tierras a nivel global.

Otro de los problemas de la tierra se refiere a la destinación o uso que se da a los predios rurales cuando la misma no es adecuada a la vocación del suelo. El Censo nacional agropecuario del año 2014 tuvo una cobertura cercana al 98\% del área rural dispersa ${ }^{17}$ continental e insular del país. Censó un total de ciento once millones quinientas mil hectáreas (111,5 millones de ha) de las cuales concluyó que la mayor parte se encuentra destinada a bosques naturales y en menor medida a uso agropecuario y uso no agropecuario (DANE, 2016, p.43) según se indica en la siguiente gráfica:

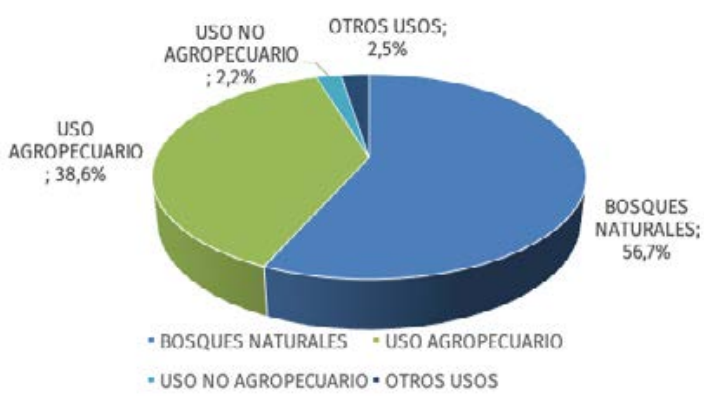

Ilustración 1. Uso y cobertura del suelo

Fuente: elaboración propia a partir de datos del DANE (2016, p.43)

El uso agropecuario referido a la siembra de cultivos, cría de animales, plantaciones forestales entre otras actividades ocupa un total de cuarenta y tres millones de hectáreas (43 millones de ha). De estas un 80\% se destina a pastos y rastrojos (para la cría de ganado principalmente), un $19,7 \%$ a uso agrícola y un 0,3 a infraestructura agropecuaria, lo cual permite afirmar que existe aún en Colombia una desproporción en el uso del suelo rural.

${ }^{17}$ Este concepto excluye los predios ubicados en cabeceras municipales y centros poblados. 
Finalmente, los problemas de despojo y abandono de predios. En total, la extensión de tierras abandonadas o despojadas en virtud del conflicto armado en el período comprendido entre los años 1980 y 2010 , asciende a poco más de 6.6 millones de hectáreas, sin contar aquellas de propiedad colectiva (Comisión de Seguimiento a la Política Pública sobre Desplazamiento Forzado, 2011, p. 8-9). Esta cifra coincide con la medición realizada por Acción Social (2010, citado por Gutiérrez, Marín, Perdomo y Machuca, 2018, p.137) que indica que las hectáreas despojadas ascienden a 6.5 millones.

Perspectiva regional y departamental

La Costa Caribe colombiana ha sido un testigo particular de los problemas relati- vos a la tierra. En cuando al acaparamiento tenemos que el coeficiente de Gini para predios muestra que a 2009 la región Caribe presentaba una elevada concentración de predios $(0,70)$, aunque inferior a la de otras regiones siendo el promedio por regiones de 0,72 . No obstante cuando se realiza el análisis con base en "propietarios sin repetición”, la región presenta una concentración de 0,82 la cual resultó muy superior al promedio de todas las regiones $(0,78)$ (Corporación PBA, 2014).

A continuación, se presentan las mediciones del coeficiente de GINI de predios para algunas de las sub-regiones del Caribe en los años 2000 y 2012:

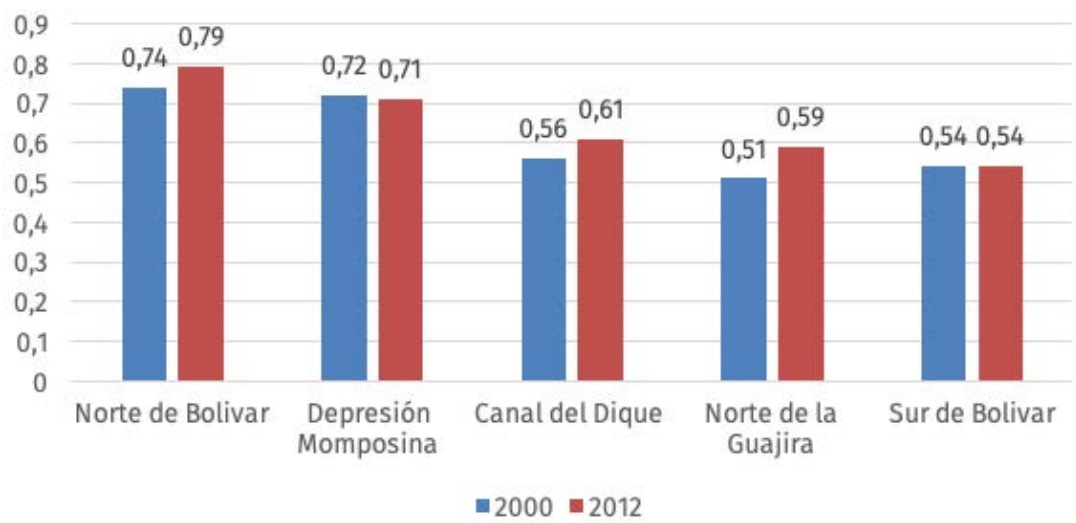

Fuente: elaboración propia con datos de la Corporación PBA, 2014, pp.32-33

Entre estas, solo en la subregión de la Depresión Momposina se evidencia una disminución en la concentración de la tierra. Las demás, como la del canal del Dique donde se encuentra el Municipio de Mahates, se mantuvieron o aumentaron los valores.

El departamento de Bolívar tiene un total de 2.574.660 hectáreas de tierra consideradas por el DANE como área rural dispersa. De estas el 41,2\% (1.061.979 ha) están destinadas a bosques naturales, el 48,7\% (1.255.959 ha) tiene un uso agropecuario, el 3,3\% (86.586 ha) se usa para actividades no agropecuarias y el $6,6 \%$ corresponde al ítem de "otros usos" según arriba se explicó (DANE, 2016, p.49).

Casi la mitad del área rural dispersa de uso agropecuario en el departamento de Bolívar (el $48.3 \%$ que equivale a 606.095 ha) no está siendo utilizada ni para agricultura, ni para ganadería, sino que constituye área en rastrojo, es decir, tierras que, si bien fueron cultivadas, no lo han sido en los últimos tres años o más al momento que el DANE realizó la entrevista del censo nacional agropecuario en 2014 (DANE, 2016, p.45). Del porcentaje restante de área agropecuaria definido en el párrafo anterior, el $32,3 \%$ (409.330 ha) se usa para pastos (des- 
tinados a la alimentación de ganado), el 18,4\% (231.194 ha) corresponde al área agrícola y el $0,7 \%$ (9.341 ha) es área destinada a infraestructura agropecuaria.

El proyecto "Piloto de Tierras de los Nuevos Territorios de Paz" implementado por la cooperación internacional

Para afrontar los problemas relativos a la tierra, la región ha sido objeto de la intervención del Estado y de la cooperación internacional. La Unión Europea ha aportado de manera importante a la creación y ejecución de programas y proyectos en beneficio de la población rural. ${ }^{18}$ Uno de los casos más importantes en los últimos años es el Programa Nuevos territorios de Paz -NTP- (convenio de financiación No. DClALA]2010/022-248 suscrito el 29 de septiembre de 2011) ${ }^{19}$ el cual fue financiado por la Comisión Europea y cuya contrapartida y administración estuvo a cargo del Departamento para la Prosperidad Social de Colombia (DPS). El programa buscó:

(...) hacer un aporte a los esfuerzos de construcción de paz y desarrollo que actualmente se están dando en el país, a través de la generación de metodologías, herramientas y rutas para la inclusión socioeconómica de la población más vulnerable y afectada por el conflicto armado, la promoción de la tenencia de la tierra y el ordenamiento territorial, así como la generación de condiciones de gobernanza democrática, participación y fortalecimiento de organizaciones sociales (Organización

\footnotetext{
${ }^{18}$ El principal programa de la Unión Europea en Colombia entre 2002 y 2010 fueron los laboratorios de paz, el cual comprendió cooperación técnica y financiera con una donación de 116 millones de dólares (Castañeda, 2009, p.164); La Unión Europea también ha aportado al financiamiento de una iniciativa de la sociedad civil denominada Programas de Desarrollo y Paz - PDP.

${ }^{19}$ Este convenio finalizó su fase ejecutiva el 29 de septiembre de 2017 de acuerdo con el adendum No. 2 del 15 de septiembre de 2016 y posteriormente su etapa de cierre se estipuló para un periodo de 12 meses, es decir. hasta 29 de septiembre de 2018.
}

Internacional para las Migraciones, 2016).

En el marco de este programa se desarrolló entre los años 2014 y 2016 el proyecto "Piloto de Tierras de los Nuevos Territorios de Paz, NTP" que tiene fundamento en el contrato de subvención 191 de 30 de diciembre de 2013 (DCI-ALA/2013/334-489) que celebró el DPS con la Organización Internacional para las Migraciones, entidad que ejecutó el proyecto. Este contrato se encuadra específicamente en el resultado dos (2) del programa NTP que buscó "fortalecer las capacidades locales para el ordenamiento del territorio, ocupación y uso de la tierra, ayudando a las comunidades a generar arraigo, salvaguardar su patrimonio, alcanzar la soberanía y seguridad alimentaria y lograr autosuficiencia" (Organización Internacional para las Migraciones, 2016, p.14). A su vez, para el desarrollo de este proyecto la OIM celebró con el Incoder el convenio 892 de 3 de diciembre de 2014 con el objeto de "aunar esfuerzos, metodologías capacidades y recursos para adelantar el proyecto piloto de tierras".

Los resultados e indicadores establecidos en el marco lógico del proyecto piloto de tierras ${ }^{20}$ se sintetizan a continuación: el primer resultado se refirió a la restitución del derecho a la tierra a hogares víctimas de despojo en los NTP, el segundo a la formalización de la propiedad sobre baldíos o predios del FNA a hogares campesinos vulnerables o víctimas del conflicto en los NTP, el tercero a la formulación de reglamentos de uso y manejo de terrenos comunales, el cuarto a la implementación de proyectos de seguridad alimentaria, con apoyo para el acceso a agua potable, mejoramiento

\footnotetext{
${ }^{20}$ El marco lógico del proyecto fue objeto de modificaciones durante la vigencia del mismo. El que se expone a continuación corresponde a modificación realizada entre marzo y abril de 2014 con el cual inicia el proyecto. Más adelante expondremos la redacción final del marco lógico.
} 
sanitario y buenas prácticas ambientales, de acuerdo a las necesidades de cada uno de los hogares que han formalizado la propiedad y el quinto al fortalecimiento de organizaciones sociales para la participación en instancias locales y regionales en la planificación y el ordenamiento del territorio, en coordinación con los socios estratégicos territoriales.

De estos, los resultados uno (1) a tres (3) son los principales y buscaron generar cambios respecto de la situación inicial de acceso, uso, y tenencia de la tierra. Adicionalmente, con exclusión del primero que se refiere a población víctima de despojo o abandono de tierras (cuestión regulada por la ley 1448 de 2011) el segundo y tercero tienen como factor diferenciador que están dirigidos principalmente a población campesina ocupante de predios de naturaleza pública, cuyo marco regulatorio es la ley 160 de 1994 y sus decretos reglamentarios. Los resultados cuarto y quinto se concibieron como un complemento para los resultados 1 a 3 (Organización Internacional para las Migraciones, 2016, p.14).

Todas estas acciones se focalizaron en municipios de los departamentos de Atlántico, Bolívar, Magdalena, Guaviare y Caquetá.

\section{La formalización en el proyecto piloto} de tierras

Como se consignó originalmente en el marco lógico del proyecto piloto de tierras, el resultado dos se refería a "formalización de la propiedad sobre baldíos y/o predios del FNA a hogares campesinos vulnerables o víctimas del conflicto en los NTP" y tenía como indicadores los siguientes:

2.1 Al finalizar el primer año 2014 se han formalizado $70 \%$ de la meta total $(770 \mathrm{Ho}-$ gares) en la tenencia de la tierra. 2.2 Al finalizar el primer trimestre del 2015 se han formalizado $30 \%$ de la meta total $330 \mathrm{Ho}-$ gares) en la tenencia de la tierra.
No obstante, el documento elaborado por la OIM y que recoge la sistematización de la experiencia hace referencia a este resultado de la siguiente manera:

(...) el objetivo del resultado de formalización era "apoyar financiera, jurídica y técnicamente, entre otros asuntos, en el trámite de algunos de sus procesos administrativos agrarios con el objetivo de formalizar 1.100 predios a hogares campesinos vulnerables o víctimas del conflicto, en las regiones definidas por el programa NTP (Organización Internacional para las Migraciones, 2016, p.84).

Si bien las diferentes redacciones del resultado dejan algunas dudas sobre las metas que se plantearon en relación con la formalización, de lo transcrito se pueden recuperar dos elementos coincidentes:

»El resultado se refería a formalizar efectivamente 1.100 predios rurales, es decir, seguir el trámite que correspondiera según la naturaleza y la situación jurídica del predio, hasta la etapa de registro en la ORIP, quedando el bien bajo la titularidad del beneficiario.

» Se trataba de bienes de naturaleza pública, ya sea baldíos o del Fondo Nacional Agrario.

Sin embargo, en el curso de la intervención este resultado fue objeto de modificación. Las razones para dicho cambio consisten en la insuficiencia de tiempo, cambios internos de las entidades que se hallaban involucradas, falta de certeza sobre la situación de tenencia de los predios en la zona por las deficiencias de la información institucional, entre otras. El resultado dos terminará siendo el siguiente: "Acompañamiento para formalización de la propiedad a favor de hogares campesinos vulnerables o víctimas del conflicto en los NTP" (Organización 
Internacional para las Migraciones, 2016, p.84). La nueva redacción llevó consigo dos cambios fundamentales:

» Los predios susceptibles de formalización no serían solo aquellos de naturaleza pública, sino también predios privados.

» La OIM dejaba de comprometerse con una formalización efectiva de los predios, transformando su compromiso al solo acompañamiento, es decir, dejó de ser una obligación de resultado y se convirtió en una de medio. El resultado se cumpliría con la asesoría sin importar si se titulaba la propiedad.

En la etapa inicial del proyecto el acompañamiento lo dirigió al Incoder, brindando asistencia técnica que facilitara la toma de decisiones en los procedimientos de titulación de baldíos, para pasar luego a dirigir ese acompañamiento directamente a los hogares campesinos vulnerables o víctimas del conflicto armado (Organización Internacional para las Migraciones, 2016, p.84).

En cuanto a la metodología se tiene que el trabajo de campo inicia con la convocatoria. Como se pudo determinar en las entrevistas, esta fue abierta para todos los pobladores del municipio, incluyendo los corregimientos y se realizó a través de comunicación directa a las diferentes asociaciones de campesinos e inclusive por radio. Así lo indica el testimonio de un funcionario público que para efectos de esta investigación llamaremos Julio (24 de febrero de 2019) quien expresa:

(...) se hizo una convocatoria masiva en cada uno de los corregimientos para mirar la posibilidad y ahorrarle el costo a las personas que se podían beneficiar de esto y no quedaran excluidas por falta de, por factores económicos para movilizarse hasta la cabecera municipal porque se hizo, primero se hizo acá, posterior a eso fuimos a cada uno de los corregimientos.
En esto coincide también el testimonio de otro de los entrevistados, en este caso campesino y beneficiario del proyecto en la Vereda Paraíso al que en adelante llamaremos Armando (24 de febrero de 2019) cuando indica:

Bueno, nosotros acá tenemos una comunidad en Paraíso y cada vez que oye un programa nos lo hacen saber o nos citan para la reunión o nos convocan a dicho evento y así participamos casi toda la comunidad. Al principio le diría que fuimos convocados por la misma comunidad de acá de Paraíso.

Hecha la convocatoria la OIM procedió con las jornadas de recolección de solicitudes individuales. A esto siguió un trámite que incluye la visita al predio para su georreferenciación, caracterización y la realización de estudios técnicos y jurídicos con el objetivo de determinar la naturaleza jurídica del predio objeto de la solicitud y la ruta que se debe seguir para titularlo a favor del solicitante. El producto concreto del proyecto piloto de tierras en el componente de acompañamiento a la formalización consistió en la conformación de expedientes para iniciar el proceso de formalización, los cuales están compuestos de los siguientes insumos: plano de levantamiento topográfico, caracterización agro-técnica, ruta jurídica, informe técnico, minutas, formatos de solicitud. Estos insumos fueron entregados a los beneficiarios del proyecto de forma física y digital (Organización Internacional para las Migraciones, 2016).

Es relevante antes de hablar de las incidencias del proyecto, tener en cuenta las condiciones previas que consideró la OIM como hipótesis en el marco lógico y que reflejan aquellas acciones de agentes externos o situaciones que son necesarias para el éxito de un proyecto. Entre estas están el interés de las organizaciones y sectores sociales por el desarrollo de las acciones 
propuestas, voluntad política de las territoriales del Incoder, voluntad de los hogares participantes, ausencia de actores armados ilegales, participación de las instituciones en los espacios de construcción para identificar la problemática y acuerdos con la comunidad para la intervención en cada zona e interés de las mismas para coordinar acciones para la gestión comunitaria y social, así como voluntad política de apoyar las actividades relacionadas con procesos agrarios.

Los resultados del acompañamiento a la formalización

Como se explicó líneas arriba, a partir del trabajo de campo desarrollado, el análisis de la información documental y el marco teórico que orientó la presente investigación se lograron identificar las siguientes categorías emergentes: convocatoria, incidencia, percepción frente a los resultados y modelo de intervención.

La incidencia es entonces la categoría más importante que emerge de la presente investigación. Como antes se indicó, el proyecto piloto de tierras buscaba inicialmente la formalización de la propiedad rural de familias campesinas ubicadas en los municipios focalizados, no obstante, esto tuvo algunas variaciones considerables a lo largo de su desarrollo, siendo la principal el cambio del resultado de la formalización efectiva al acompañamiento o asesoría a la formalización.

Lo primero que se puede destacar de las entrevistas, en relación con la incidencia, es que los beneficiarios tenían suficiente claridad del alcance general del proyecto. Por ejemplo, Armando (24 de febrero de 2019) ante la pregunta por las generalidades del proyecto, respondió:

(...) del año no estoy seguro, se me envolata un poco la fecha precisa, pero si fueron muy buenos proyectos que nos propusieron. Fueron también eva- luados y puestos en práctica y nos dio bastantes resultados positivos. La programación de ellos fue tratar de hacerle la escritura al predio.

Así mismo la entrevistada que en adelante llamaremos Berta (24 de febrero de 2019) responde: "nos explicaron que debíamos hacer, o sea, como legalizar nuestros predios, y recibimos dicha información".

No obstante, estas personas, tanto las que atendieron la entrevista, como en general todas aquellas que participaron del proyecto, esperaron más allá de la simple comprensión del proyecto recibir un beneficio concreto, el cual se puntualiza, pudo estar representado en: a) la titulación del predio (aunque no fuera el resultado esperado al final de la intervención, si lo era al inicio) o b) en el acompañamiento y entrega documentos sobre la caracterización del mismo. La incidencia también se mide por este aspecto.

En cuanto lo anterior, la inquietud que surgió fue ¿A cuántas personas y de qué manera, benefició el proyecto Piloto de Tierras con su implementación en Mahates? Según la OIM (2016), el proyecto Piloto de Tierras logró el acompañamiento a la formalización de 1106 solicitudes de las cuales 530 pertenecen a Caquetá y 576 al Canal del Dique Zona Costera (Donde 25 solicitudes fueron declaradas no viables). En Bolívar, que hace parte de esta última zona, la acción se focalizó en el municipio de Mahates y sus corregimientos, donde se recibieron un total de trescientas siete (307) solicitudes de acompañamiento a la formalización de la propiedad de las cuales 230 corresponden a procesos administrativos, ${ }^{21} 25 \mathrm{a}$

\footnotetext{
${ }^{21}$ Se aclara que la categoría de procesos administrativos puede referirse en el marco del proyecto tanto a la falta de registro de títulos (Escritura Pública, Sentencia o resolución de adjudicación del antiguo Incoder) ante la ORIP, como a falta de títulos legalmente constituidos o protocolizados (como cuando se realiza una venta por medio de documento privado debiendo ser por escritura pública) e inclusive a la ocupación de predios baldíos.
} 
procesos judiciales y 52 a otros trámites no especificados.

Durante la investigación se lograron recabar dos casos correspondientes a la primera categoría. En ambos el estudio realizado por la OIM identificó la naturaleza jurídica de los predios como bienes baldíos por lo que el trámite de titulación consiste en presentar solicitud de adjudicación ante la ANT, entidad competente según dispone el artículo 24 del decreto 2363 de 2015, para lo cual se debe considerar el cumplimiento por parte del solicitante de los requisitos establecidos en la ley 160 de 1994 y el decreto reglamentario 1071 de 2015 para ser sujeto de reforma agraria, ${ }^{22}$ es decir, adjudicatario de un bien que perteneciera a la nación.

Un número significativamente menor corresponde a aquellos beneficiarios cuyo predio solo podría ser formalizado a través de un trámite judicial ${ }^{23}$ como constatamos en otro de los casos recabados en la investigación, el de Berta, habitante del casco urbano del municipio de Mahates cuyo predio, según el estudio de la OIM debe someterse al trámite pertenencia agraria definido en la ley 1561 de 2012.

Al final del estudio técnico y jurídico la OIM entregaría como producto final un expediente con la documentación necesaria para que los beneficiarios pudieran seguir en una instancia diferente a la del proyecto piloto, la formalización de su predio. Todos los entrevistados afirmaron haber recibido su expediente. Berta (24-02-2019) dice por ejemplo:

\footnotetext{
${ }_{22}$ Para ser sujeto de reforma agraria se requiere: a. haber ocupado y explotado un predio con aptitud agropecuaria al menos durante 5 años (art. 65 ley 160 de 1994). B. NO ser propietario ni poseedor de otro inmueble Art. 72 ley 160. c. No tener patrimonio neto sea superior a mil salarios mínimos mensuales legales (art. 71 ley 160).

${ }^{23}$ Entre estos se encuentran los procesos de pertenencia para aquellos casos en que los solicitantes son poseedores de predios de naturaleza privada, los procesos sucesorios cuando fallecido el propietario del bien inmueble, sus herederos (hijos, padres, cónyuge, etc) no han realizado el trámite de la sucesión (aunque esta también puede llevarse por vía administrativa ante notario cuando todos los herederos están de acuerdo).
}

Todo, yo tengo todos los documentos que la OIM me entrego para así. O sea ellos me dicen que todo está listo. Ya lo que dependía de nosotros. (¿Qué tipo de documentación le fue entregada?) Si este digamos hay un cd donde tiene toda la información. Los datos del topógrafo, el croquis del terreno, los planos más detallados del que teníamos antes. Solo teníamos una compraventa. Ahora solo falta el título a favor de nosotros pero ya todos los trámites están hechos.

Lo anterior se pudo constatar de forma directa con Carlos (24 de febrero de 2019) y Martha, otra de las entrevistadas, habitante del casco urbano del municipio de Mahates, quienes permitieron que se revisara su expediente.

Pero ante todo el andamiaje que apareja una intervención como esta, la pregunta sobre la utilidad que representó para los participantes el haber recibido información detallada tanto técnica como jurídica sobre su predio, cobra relevancia. La respuesta a este cuestionamiento no puede ser definitiva ni generalizadora. En primer lugar, por haberse realizado una priorización de solicitudes y en segundo lugar porque al finalizar la intervención, la formalización de la mayoría de los predios quedó a discreción de los beneficiarios, lo que pasa a explicarse.

En relación con la priorización, se pudo constatar que del universo de solicitudes presentadas (307 en total) y luego de haber realizado el estudio correspondiente, la OIM seleccionó sesenta y dos (62) familias con viabilidad para la formalización pero posteriormente se redujo este número a solo dieciocho (18), como así lo indicó el funcionario Julio quien prosigue explicando que esta focalización obedeció a que "cuando fueron estudiando los casos un poquito más a fondo se van dando cuenta y le van encontrando algunas trabas" por lo que se escogen finalmente a dieciocho familias, las cuales se encuentran distribuidas en los corregimientos de Malagana, Paraíso, Mandinga, Evitar y Gamero. 
Es por lo anterior que la titulación, como beneficio o impacto planificado se puede catalogar como un fracaso. No se logró materializar las expectativas que inicialmente se tenían, pues de 307 solicitudes recibidas solo dieciocho fueron viables, sin lograrse a la fecha de las entrevistas, la formalización de ningún predio.

Por otra parte, a pesar de haberse hecho una actividad de cierre del proyecto en el año 2016, durante los años 2017 y 2018 se siguieron desarrollado algunas acciones con miras a lograr la formalización de los dieciocho predios seleccionados del universo de solicitudes inicial, lo que nos llevó a identificar una tercera microcategoría dentro de la categoría de incidencia, el seguimiento.

Como se dijo, entre los entrevistados se encontraba Ramón (24 de febrero de 2019), quien tenía la calidad de funcionario público y a su vez, de beneficiario. El conocimiento de su caso fue avocado por la Agencia Nacional de Tierras según consta en auto No. 54 de 20 de febrero de 2018. En dicha providencia se lee:

Que en fecha 20 de febrero de 2018 , el Departamento para la Prosperidad Social radicó ante la Agencia Nacional de Tierras las solicitudes que habían sido recepcionadas en su momento por la Organización Internacional para las Migraciones toda vez que dichos procesos fueron priorizados para lograr su finalización en el marco del convenio interadministrativo 530 de 2017 celebrado entre el Departamento para la Prosperidad Social y la Agencia Nacional de Tierras (...)

No obstante, a febrero de 2019, época en que se realizó las entrevista aún no le había sido notificado ningún avance del proceso al beneficiario.

Por otra parte, están los beneficiarios que no fueron "priorizados". Para ellos la formalización queda a discreción de sus posibilidades económicas, siempre y cuando hubieren comprendido que lo recibido es apenas un insumo para que por su propia iniciativa procuren la titulación de su predio. Estos, al igual que todos, recibieron la carpeta con la información técnica y jurídica del predio en el momento en que finalizó su proceso de acompañamiento en 2016. No obstante, desde esa época, al menos los beneficiarios entrevistados, no habían realizado trámite alguno. Uno de ellos, Berta (24 de febrero de 2019), manifiesta que los asesores le dijeron lo que debía hacer: "Ir a un consultorio jurídico de una Universidad y solicitar un abogado para que (le) pasaran el caso hacia el juzgado de Mahates para que el juzgado (le) diera la aprobación del predio".

Lo anterior por cuanto al finalizar el proyecto la OIM buscó generar algunas alianzas que permitieran a los beneficiarios iniciar o continuar su trámite de formalización de la propiedad. Es así como realizó acercamientos con la Universidad del Norte en Barranquilla, la de San Buenaventura y la Universidad de Cartagena para que a través de sus consultorios jurídicos ofrecieran acompañamiento y asesoría gratuita a la población. No obstante, esta iniciativa no logró concretarse en un acuerdo formal (OIM, 2016, pp.104-105).

Adicionalmente, como se constató en folleto informativo suministrado durante el evento de socialización de resultados realizado el día 25 de agosto de 2016 en Cartagena, la OIM procuró promover en los beneficiarios la iniciativa de acudir ante las entidades competentes con el fin de hacer seguimiento a los procesos de formalización que estuvieran en curso y requerir en caso de ser necesario, su efectivo trámite. Por otra parte, se involucró en el proceso a las autoridades locales como la Alcaldía Municipal de Mahates de tal manera que asumieran el compromiso de acompañar los procesos judiciales y administrativos "que se adelanten a favor de los campesi- 
nos, brindando apoyo jurídico para la correcta finalización de los mismos". Así mismo el Departamento para la Prosperidad Social sería responsable de brindar medios que facilitaran la continuación de los procesos imprimiendo celeridad a los trámites y velando por su exitosa terminación.

Finalmente, la Agencia Nacional Tierras sería la encargada de iniciar los procedimientos de adjudicación de baldíos y predios del fondo nacional agrario y de tramitar las autorizaciones correspondientes cuando se tratare de enajenaciones (toda vez que los predios adjudicados o sometidos a régimen parcelario tienen limitaciones a la facultad de disposición que un propietario tiene sobre el predio del cual es titular, como por ejemplo para vender) y fraccionamientos de las parcelas. Estos compromisos si bien no reposan en el informe de sistematización de los resultados, publicado por la OIM en agosto de 2016, pudieron ser constatados conforme al folleto informativo arriba citado y en el auto No. 54 de 20 de febrero de 2018 emitido por la ANT y que fue suministrado por Ramón.

La cuarta de las microcategorías dentro de la incidencia es el aprendizaje sobre proceso de formalización. Esta emerge del hecho de que los beneficiarios podían identificar la naturaleza jurídica del predio, de que comprendían la razón por la cual su predio no había sido formalizado y en general tenían mayor claridad sobre la situación jurídica del mismo. En relación con esto la OIM destaca en su sistematización algunos logros que van más allá de los resultados esperados en el marco lógico, como la garantía de los derechos de los campesinos quienes a partir de la intervención tienen mayor claridad sobre la situación jurídica de sus predios y la manera de formalizarlos.

Además de la convocatoria y la incidencia hasta aquí analizadas, otra de las categorías emergentes fue la percepción frente a los resultados. En general puede afirmar- se que existe un sentimiento de agradecimiento por parte de la población beneficiaria. Armando, de la vereda Paraíso, Berta del casco urbano de Mahates y Julio (funcionario público) por ejemplo, valoraron el proyecto como "excelente". Carlos por su parte dijo:

Por eso ha sido bueno porque me está dando a partir de estos documentos que soy el legítimo propietario y que ya yo puedo a través de un banco hacer un proyecto productivo y certificarlo con mis documentos de mi tierra.

Si bien se refleja cierta confusión en relación con la titulación de su predio que aún no se ha concretado, es claro que está conforme con la intervención, aunque identifica algunos aspectos a mejorar como:

Vamos a poner que duró un año en cuanto a la escritura ya original que me la hubieran entregado y me dijeran ya hicimos esto vamos a hacer este proyecto productivo aquí en su finca. Ahí me sentiría el $100 \%$ más satisfecho.

Finalmente, la última categoría está referida al modelo de intervención. Indica la OIM que con el proyecto se logró "el diseño y la puesta en marcha de un modelo de intervención para la formalización de predios rurales" (OIM, 2016, p.104) que vincula el aspecto institucional, un trabajo jurídico y técnico y la participación activa de la comunidad y que se puso en evidencia las discrepancias y vacíos de información de las autoridades locales y nacionales, la desarticulación entre las instituciones (como el catastro y el registro) y la desactualización de la información catastral.

Sobre la base de estos logros se precisa que, siendo un proyecto piloto, es consecuente que el mismo ofreciera un "modelo de intervención" para abordar el problema de la informalidad de la tierra, no obstante, los resultados hasta aquí descritos permi- 
ten cuestionar su viabilidad. Si bien se prestó un acompañamiento, las acciones ulteriores realizadas por el DPS sobre los casos priorizados evidencian que un programa de corto plazo no es una opción, frente a la complejidad de los problemas que afronta el sector rural.

\section{Conclusiones}

Inicialmente, sobre los instrumentos internacionales relativos a la gestión de la tierra y los derechos de los campesinos, Ilama la atención que en su mayoría hacen parte de lo que se conoce como SOFT LAW, es decir, acuerdos o declaraciones que no son vinculantes u obligatorios para los Estados, de lo cual deriva también su falta de eficacia.

Como conclusión principal del estudio de caso se tiene que la OIM cumplió en forma satisfactoria con el resultado 2 del Proyecto Piloto de Tierras que luego de las modificaciones realizadas en medio de la intervención consistía en un acompañamiento o asesoría técnico - jurídica. No obstante, no se puede dejar de lado el hecho de que la aspiración planteada originalmente y con la cual inició la ejecución se refería a una formalización efectiva. En este sentido se puede afirmar que la incidencia de la cooperación internacional representada en la Unión Europea como principal financiador del proyecto, fue prácticamente nula en cuanto a los beneficios obtenidos por los participantes del mismo, pues no logró transformar la situación inicial de informalidad en la tenencia de la tierra en el municipio de Mahates.

La OIM hizo un esfuerzo importante para procurar que familias campesinas vulnerables accedieran a la propiedad de un predio que bien poseen u ocupan, para lo cual desplegó un equipo técnico y jurídico que generó gran expectativa en la comunidad. Los resultados, sin embargo, son contundentes. No se habla de predios formalizados a la fecha (aún después de casi tres años de finalizado el proyecto) y esto se explica en la voz de la OIM por varias razones que resultan válidas, pero a su vez, predecibles, como lo son los problemas conexos a la informalidad.

Frente a las expectativas de la comunidad se comprobó la importancia de que las entidades que desarrollan proyectos en beneficio de personas vulnerables sean transparentes en relación con los alcances reales de los mismos. Fue evidente que, aunque no se lograra la formalización, la comunidad manifestó en todo momento un sentimiento de agradecimiento por la intervención que realizó la OIM en su territorio y la mayor claridad que tienen actualmente sobre sus derechos sobre la tierra.

Sobre la planeación del proyecto se comprobó la importancia de considerar con carácter principal las hipótesis que se proponen en el marco lógico. En el presente caso una circunstancia no considerada se sumó a los problemas que dieron al traste con las aspiraciones de la OIM de lograr resultados significativos y fue la transición institucional más importante que ha tenido el sector rural en los últimos años: la liquidación del Incoder y la aparición de las agencias que pasarían a ser los entes principales para la gestión del desarrollo rural, como son: Agencia Nacional de Tierras, La Agencia de Desarrollo Rural y la Agencia de Renovación del Territorio. Un cambio que sin duda era necesario, terminó obstaculizando las aspiraciones de la OIM, no solo de lograr alguna formalización efectiva, aunque no estuvieran en principio obligados a ello por el cambio del resultado segundo del proyecto, sino porque impidió obtener información importante para la definición de rutas jurídicas, específicamente resoluciones de adjudicación asociadas a las solicitudes.

Otro tema importante es la metodología desarrollada por la OIM pues la entidad la considera un aporte del proyecto por haberse diseñado y puesto en práctica un modelo 
de intervención para la formalización de predios rurales. Sobre esto es importante destacar el carácter individualizador de la metodología, lo cual se aprecia desde la forma en que los campesinos fueron adhiriéndose al programa. De esto se derivó la gran dispersión de las solicitudes que, si bien se enmarcan en un mismo municipio, se ubican en corregimientos distantes unos de otros, no generándose por tanto un impacto significativo en ninguna de las comunidades de los participantes.

1. Con el estudio se confirman dos consideraciones expuestas en los capítulos primero y segundo del artículo: La primera relativa a la poca eficacia de los programas de Cooperación Internacional para llevar a la práctica las políticas concebidas en pro del desarrollo. La segunda, de la misión para la transformación del campo según la cual el éxito del proceso de formalización no se garantiza con la tramitación de solicitudes individuales, debiéndose recurrir a la estrategia de barrido predial que implica intervenciones masivas en los municipios pues resulta más efectiva.

2. La informalidad en la tenencia de la tierra no es solo un problema de falta de voluntad o desconocimiento por parte de sus poseedores u ocupantes de los requisitos para transferir o transmitir el dominio. Por ello no se resuelve brindando claridad sobre la situación jurídica de los predios. El problema en cuestión es parte de la debilidad estructural del sector agrario que aqueja los mismos problemas de hace décadas. Por esto sorprende que uno de los resultados destacables del proyecto sea que se puso en evidencia las discrepancias y vacíos de información de las autoridades locales y nacionales, la desarticulación entre las instituciones (como el catastro y el registro) y la desactualización de la información catastral, temas extensamente diagnosticados por las autoridades y organismos diversos en el ámbito nacional e internacional.
3. La formalización de propiedad rural amerita una acción coordinada con las entidades gubernamentales encargadas de la política de tierra, por lo cual los ejecutores de los proyectos deben establecer alianzas con los actores estratégicos tanto en el marco nacional como en terreno. Es importante realizar un buen estudio previo de actores buscando prever cambios institucionales que puedan frustrar el éxito del proyecto.

El factor tiempo es crucial. Por tratarse de formalización de propiedad rural, los proyectos que se propongan abordar el tema deberían plantearse un término prudente que, teniendo en cuenta la demora de los trámites judiciales y administrativos, oscilaría entre los cuatro y seis años. Inclusive las agencias donantes deben plantearse esta cuestión y plasmarlo así en sus convocatorias de financiación, pues de ella depende que el dinero a invertir se convierta en resultados alcanzados. 
Referencias

Agudelo, J. (2014). Marco Conceptual de la Cooperación Universitaria. Revista Internacional de Cooperación y Desarrollo, 1(1), 110-135.

Banco Mundial. (2013). Mejora de la gobernanza de la tierra en Colombia. Bogotá: Banco Mundial.

Banco Mundial. (14 de Octubre de 2018). Doing Business. Recuperado de http://espanol.doingbusiness.org/es/about-us

Banco Mundial. (2018). Doing Business 2018. Reforming to create jobs. Washington D.C.: Banco Internacional para la Reconstrucción y el Desarrollo.

Banco Mundial. (2018). SDG atlas 2018. Recuperado de http://datatopics.worldbank.org: http://datatopics.worldbank. org/sdgatlas/SDG-01-no-poverty.html

Berry, A. (2002). ¿Colombia encontró por fin una reforma agraria que funcione? Revista de Economía Institucional, 4(6), 24-70.

Casilda, R. (2004). America latina y el Consenso de Whashington. Boletín Económico de ICE, 19-38.

Castañeda, D. (2009). ¿Que significan los laboratorios de paz para la unión Europea? Colombia Internacional, 69, 162-179.

Ceelat. (6 de Junio de 2016). Mapa de concentración de la tierra en Colombia. www.ceelat.org. Recuperado de http:// ceelat.org/mapas/mapa-de-concentracion-de-la-tierra-en-colombia/

Celac. (17 de Febrero de 2019). Plataforma de seguridad alimentaria y nutricional. Recuperado de https://plataformacelac.org/ programa/367

Centro Nacional de Memoria Historica. (2013). La política de reforma agraria y tierras en Colombia. Esbozo de una memoria institucional. Bogotá: Imprenta Nacional.

Cepal. (14 de Octubre de 2018). Comisión Económica para América Latina y el Caribe. Recuperado de https://www.cepal.org/es/ temas/objetivos-de-desarrollo-del-milenio-odm/objetivos-metas-indicadores-odm\#ODM1
Coalición Internacional para el Acceso a la Tierra. (2015). Estrategia 2016 - 2021. Roma: David Wilson.

Comisión de Estadistica de Naciones Unidas. (10 de Julio de 2017). A/RES/71/313. Marco de indicadores mundiales para los $\mathrm{Ob}$ jetivos de Desarrollo Sostenible y metas de la Agenda 2030 para el Desarrollo Sostenible. Nueva York, Estados Unidos de America: ONU.

Comisión de seguimiento a la política pública sobre desplazamiento forzado. (2011). El reto ante la tragedia humanitaria del desplazamiento forzado. Reconocer y resarcir los daños y perjuicios. Bogotá: Torre Gráfica.

Corporación PBA. (2014). Informe Técnico: Lineamientos y estrategias de desarrollo rural territorial para la región Caribe colombiana. Serie Documentos de Trabajo $N^{\circ} 142$. Grupo de Trabajo: Desarrollo con Cohesión Territorial. Programa Cohesión Territorial para el Desarrollo. Santiago, Chile: Rimisp.

DANE. (2016). 3er. Censo Nacional Agropecuario. Tomo 2 -Resultados. Bogota D. C.:

FAO. (13 y 17 de Noviembre de 1996). Cumbre mundial sobre la alimentación. Recuperado de www.fao.org: http://www.fao. org/3/W2612S/w2612s06.htm

FAO. (2012a). Dinamicas del mercado de la Tierra en America latina y el Caribe: concentración y extranjerización. Roma: Fernando Soto y Sergio Gómez.

FAO. (2012b). El estado de los recursos de tierras y aguas del mundo para la alimentación y la agricultura. La gestión de los sistemas en situación de riesgo. Madrid: Mundi-Prensa.

FAO. (2014). Reflexiones sobre la concentración y la extranjerización de la tierra en America Latina y el Caribe. Roma: Fernando Soto y Sergio Gómez.

FARC-EP. (2 de Abril de 1993). Bloque martin Caballero. Farc-EP. Recuperado de https://resistencia-colombia.org/farcep/documentos/157-programa-agrario-de-los-guerrilleros-de-las-farc-ep 
Gobierno nacional de Colombia - FARC-EP. (24 de Noviembre de 2016). Acuerdo final para la terminación del conflicto y la construcción de una paz estable y duradera. Bogotá, Colombia.

Gutierrez, F., Marín, M., Perdomo, P., y Machuca, D. (2018). Arañando la superficie: subestimaciones sistemáticas en la política de restitución y sus fuentes. Revista Estudios Socio-Jurídicos, 133-177.

Instituto Geográfico Agustín Codazzi. (2012). Atlas de la distribución de la propiedad rural en Colombia. Bogotá: Imprenta Nacional de Colombia.

LeGrand, C. (1988). Colonización y protesta campesina en Colombia. Bogotá: Centro Editorial Universidad Nacional de Colombia.

Londoño, M. (2008). La congestión y la mora judicial, el juez ¿su unico responsable? Facultad de Derecho y Ciencias Políticas, 385-419.

Machado, A. (2009). La opción de la reforma rural. En A. Machado, La reforma rural, una deuda social y política (pp.87-114). Bogotá: Universidad Nacional de Colombia.

Misión para la transformación del campo. (2015). El campo colombiano: un camino hacia el bienestary a paz. Bogotá D. C.: Departamento Nacional de Planeación.

Oficina Regional de la Fao para América Latina y el Caribe. (5 de Abril de 2017). FAO. Recuperado de http://www.fao.org/ americas/noticias/ver/es/c/879000/

ONU. (14 de Agosto de 1992). Declaración autorizada, sin fuerza jurídica obligatoria, de principios para un consenso mundial respecto de la ordenación, la conservación y el desarrollo sostenible de los bosques de todo tipo. Recuperado de https://www. un.org/documents/ga/conf151/spanish/ aconf15126-3annex3s.htm
ONU. (1992 de Junio de 1992). Declaración de Rio sobre el Medio Ambiente y el DesarroIlo. Recuperado de www.un.org: https:// www.un.org/spanish/esa/sustdev/agenda21/riodeclaration.htm

ONU. (17 de junio de 1994). Convención de las Naciones Unidas de lucha contra la desertificación en los países afectados por la sequía grave o la desertificación, en particular en África. Recuperado de https://www. un.org/es/events/desertificationday/ convention.shtml

ONU. (13 de Septiembre de 2000). Declaración del Milenio. Recuperado de www. un.org: https://www.un.org/spanish/milenio/ares552.pdf

ONU. (4 de Septiembre de 2002). Declaración de Johannesburgo sobre el Desarrollo Sostenible. Recuperado de www.un.org: https://www.un.org/spanish/esa/sustdev/WSSDsp_PD.htm

ONU. (2010). Gestión Integrada de los Recursos Hídricos. Guía de lectura. Recuperado de https://www.un.org/ waterforlifedecade/pdf/05_2010_reader_iwrm_eng.pdf

ONU. (2015). Objetivos de Desarrollo del Milenio. Informe de 2015. Nueva York: ONU.

ONU. (2018). Día mundial de la lucha contra la desertificación. Recuperado de https:// www.un.org/es/events/desertificationday/background.shtml

Organización Internacional para las Migraciones. (2016). La política de tierras y desarrollo rural. Desafíos y oportunidades para el posconflicto. La experiencia del proyecto piloto de tierras en el marco de los nuevos territorios de paz. Bogotá, Colombia: OIM.

Palacios, M. (2011). ¿De quién es la tierra?: propiedad, politización y protesta campesina en la década de 1930. Bogotá: FCE, Universidad de los Andes. 
Procuraduría Ceneral de la Nación. Delegada para asuntos ambientales y agrarios. (2015). Reflexiones sobre el Incoder y la Institucionalidad Agraria en Colombia. Informe preventivo. Bogotá: Instituto de Estudios del Ministerio Público.

Programa de Naciones Unidas para el Desarrollo. (3 de Febrero de 2018). Recuperado de http://www.undp.org/content/ undp/es/home/sustainable-development-goals.html
Puello, A. (2018). Reforma rural integral para la paz. En I. Blanco, Perpectivas frente a la paz, la justicia y las instituciones sólidas. Retos del ODS 16. (pp.106-146). Cartagena de Indias: Alpha.

Real Academia Española. (28 de Julio de 2019). Diccionario de Español. Recuperado de https://dle.rae.es/srv/search?m=30\&w=incidencia

UPRA. (2014). Bases conceptuales de los procesos de regularización de la propiedad rural y aceso a tierras. Bogotá D.C.: UPRA. 